\title{
High nuclear MSK1 is associated with longer survival in breast cancer patients
}

\author{
Xuan Pu ${ }^{1} \cdot$ Sarah J. Storr ${ }^{1} \cdot$ Narmeen S. Ahmad ${ }^{1} \cdot$ Emad A. Rakha ${ }^{2} \cdot$ Andrew R. Green $^{2} \cdot$ Ian O. Ellis ${ }^{2}$. \\ Stewart G. Martin ${ }^{1}$ (1)
}

Received: 21 December 2017 / Accepted: 6 January 2018 / Published online: 11 January 2018

(c) The Author(s) 2018. This article is an open access publication

\begin{abstract}
Purpose Mitogen- and stress-activated kinases (MSKs) are important substrates of the mitogen-activated protein kinase (MAPK)-activated protein kinase family. MSK1 and MSK2 are both nuclear serine/threonine protein kinases, with MSK1 being suggested to potentially play a role in breast cancer cell proliferation, cell cycle progression, cell migration, invasion and tumour growth. The aim of the current study was to assess MSK1 protein expression in breast cancer tumour specimens, evaluating its prognostic significance.

Methods A large cohort of 1902 early stage invasive breast cancer patients was used to explore the expression of MSK1. Protein expression was examined using standard immunohistochemistry on tissue microarrays.

Results Low MSK1 protein expression was associated with younger age $(P=0.004)$, higher tumour grade $(P<0.001)$, higher Nottingham Prognostic Index scores $(P=0.007)$, negative ER $(P<0.001)$ and PR $(P<0.001)$ status, and with triplenegative $(P<0.001)$ and basal-like $(P<0.001)$ phenotypes. Low MSK1 protein expression was significantly associated with shorter time to distant metastasis $(P<0.001)$, and recurrence $(P=0.013)$ and early death due to breast cancer $(P=0.01)$. This association between high MSK1 expression and improved breast cancer-specific survival was observed in the whole cohort $(P=0.009)$ and in the HER2-negative and non-basal like tumours $(P=0.006$ and $P=0.024$, respectively). Multivariate analysis including other prognostic variables indicated that MSK1 is not an independent marker of outcome.

Conclusions High MSK1 is associated with improved breast cancer-specific survival in early stage invasive breast cancer patients, and has additional prognostic value in HER2-negative and non-basal like disease. Although not an independent marker of outcome, we believe such findings and significant associations with well-established negative prognostic factors (age, grade, Nottingham Prognostic Index, hormone receptor status, time to distant metastasis, recurrence and triple-negative/ basal-like status) warrant further examination and validation in independent patient cohorts.
\end{abstract}

Keywords Breast cancer $\cdot$ MSK $\cdot$ Breast cancer-specific survival · Biomarker

Stewart G. Martin

stewart.martin@nottingham.ac.uk

1 University of Nottingham, Division of Cancer and Stem Cells, Department of Clinical Oncology, School of Medicine, Nottingham University Hospitals NHS Trust, City Hospital Campus, Nottingham, UK

2 University of Nottingham, Division of Cancer and Stem Cells, Department of Histopathology, School of Medicine, Nottingham University Hospitals NHS Trust, City Hospital Campus, Nottingham, UK

\section{Background}

Mitogen- and stress-activated kinases (MSKs), nuclear serine/threonine protein kinases, are important substrates of the mitogen-activated protein kinase (MAPK)-activated protein kinase family [reviewed in (Cargnello and Roux 2011)]. Two novel protein kinases, MSK1 and MSK2, were originally described by Deak et al. in 1998, based on their significant similarity to the N-terminal ribosomal S6 kinases (RSKs). Human MSK1 and MSK2 are 63-75\% identical to each other, and present significant homology to RSKs (approx. 40\% similarity) (Deak et al. 1998). MSK1 and MSK2 are activated through MAPK/ERKs signalling in response to mitotic agents such as epidermal growth factor (EGF) and phorbol ester 
(TPA, 12-O-tetradecanoylphorbol-13-acetate); or through the MAPK/p38 pathway in response to stress stimuli such as UV radiation, oxidative and chemical stress (Deak et al. 1998). Both MSK1 and MSK2 are ubiquitously expressed across a variety of tissues, including heart, brain, placenta, lung, liver kidney and pancreatic tissue, with predominant expression observed in brain, placenta and skeletal muscle (Deak et al. 1998).

Many transcription factors have been identified as substrates of MSKs, and phosphorylation by MSKs can enhance their activity. MSK1/2 can phosphorylate cAMP response element-binding (CREB) protein and activating transcription factor 1 (ATF1) in response to mitogens and stress; the phosphorylation of CREB at Ser133 can regulate the transcription of several immediate early (IE) genes, including c-fos, JunB and Egr1 (Wiggin et al. 2002). MSKs contribute to regulation of histone $\mathrm{H} 3$, a component of the nucleosome, and HMGN1 (HMG-14), a chromatin-associated protein. It has been shown that stress- and mitogen-stimulated phosphorylation of histone $\mathrm{H} 3$ and HMGN1 in fibroblasts is compromised in $\mathrm{MSK}^{-1-} \mathrm{MSK}^{-/-}$mice (Soloaga et al. 2003). The physiological function(s) of MSKs remains to be completely determined; however, it has been suggested that MSK1/2 may have a role in regulating the immune system and neuronal function [reviewed in (Vermeulen et al. 2009)].

Recent studies have suggested that MSK1 may be important in the regulation of breast cancer cell progression, playing a role in steroid-hormone induced breast cancer cell proliferation (Reyes et al. 2014). Depletion of MSK1 has been shown to inhibit oestrogen (E2) or progesterone-induced breast cancer cell (T-47D) proliferation and tumour growth in hormone-dependent breast cancer xenografts (Reyes et al. 2014). Furthermore, MSK1 participates in G1-S phase transition and regulates cell cycle-associated gene expression in response to hormones, evidenced by the recruitment of MSK1 to specific PR-binding sites in chromatin (Reyes et al. 2014). Breast tumour-associated osteoblast (TAOB)-derived CXCL5 induced cell migration, and invasion of the breast cancer cell lines, MCF-7 and MDA-MB-231, is associated with increased MSK1 activation (Hsu et al. 2013). In T-47D breast cancer cells, alcohol exposure can cause increased expression and activation of proto-oncogene tyrosine-protein kinase (ROS1), which induces MSK1 activation through the MAPK/ERKs pathway (Lee et al. 2013).

The aim of the current study was to assess MSK1 protein expression in a large cohort of breast cancer tumour specimens, evaluating its prognostic significance.

\section{Methods}

\section{Clinical samples}

This immunohistochemical-based study was performed using a cohort of early stage breast cancer patients $(n=1902)$ treated at Nottingham University Hospitals, with long-term follow-up, between 1986 and 1998. Information on clinical history, outcome and tumour characteristics was collected and assessed in a standardised manner, including age at diagnosis, tumour size, histologic stage and grade, Nottingham prognostic index (NPI), lymphovascular invasion (LVI), oestrogen receptor (ER), progesterone receptor (PR) and human epidermal growth factor receptor 2 (HER2) status. ER, PR and HER2 status were available for this cohort and have been described previously (Abdel-Fatah et al. 2010). HER2 positivity expression was determined by immunohistochemistry (IHC) with fluorescence in situ hybridisation (FISH), and FISH was performed for the cases with IHC scored as 2+. Basallike phenotype was defined as the expression of cytokeratin (CK)-5/6 and/or CK-14 expression in 10\% or more of invasive tumour cells, irrespective of ER, PR or HER2 status (Rakha et al. 2006). The median age of the patients was 55 years (ranging from 18 to 72), and 63.2\% (1203 of 1902) of patients had stage I disease. Breast cancer-specific survival was defined as the time interval (in months) from the date of primary surgery to death resultant from breast cancer. The median follow-up time was 177 months (ranging from 1 to 308 months). Patients were managed under a uniform protocol, where all underwent wide local excision $(n=819,43.1 \%)$ or mastectomy $(n=1067$, $56.1 \%$ ), and approximately half of the patients received radiotherapy $(n=1025,53.9 \%)$. Systemic adjuvant treatment was given based on ER, menopausal status and NPI values. Patients with ER-positive disease were chosen for hormone therapy $(n=674,35.4 \%)$. Patients with ER negative or premenopausal status were chosen for CMF chemotherapy (cyclophosphamide, methotrexate and 5-fluorouracil, $n=320,16.8 \%$ ), if they had an NPI value of 3.4 or above, whereas patients who had an NPI value less than 3.4 did not receive adjuvant chemotherapy. This study is reported in accordance with REMARK criteria (McShane et al. 2005). Nottingham Research Ethics Committee 2 approved the project under "Development of a molecular genetic classification of breast cancer R\&D "(No. $03 \mathrm{HI} 01$ REC Ref.C202313)”. The clinicopathologic variables of the patient cohort are shown in Table 1 . 
Table 1 Clinicopathologic variables of breast cancer patient cohort

\begin{tabular}{|c|c|}
\hline Variables & No. $(\%)$ \\
\hline Age (mean $\pm S D$, years) & $54.25( \pm 9.77)$ \\
\hline$\leq 40$ years & $165(8.7 \%)$ \\
\hline$>40$ years & $1736(91.3 \%)$ \\
\hline ND & $1(0.1 \%)$ \\
\hline Tumour size (mm) & $2.06 \pm 1.14$ \\
\hline$\leq 20 \mathrm{~mm}$ & $1185(62.3 \%)$ \\
\hline$>20 \mathrm{~mm}$ & $708(37.2 \%)$ \\
\hline ND & $9(0.5 \%)$ \\
\hline \multicolumn{2}{|l|}{ Tumour stage } \\
\hline I & $1203(63.2 \%)$ \\
\hline II & $531(27.9 \%)$ \\
\hline III & $160(8.4 \%)$ \\
\hline ND & $8(0.4 \%)$ \\
\hline Tumour grade & $346(18.2 \%)$ \\
\hline \multicolumn{2}{|l|}{ I } \\
\hline II & $632(33.2 \%)$ \\
\hline III & $915(48.1 \%)$ \\
\hline ND & $9(0.5 \%)$ \\
\hline NPI & $4.16 \pm 1.18$ \\
\hline$\leq 3.4$ & $619(32.5 \%)$ \\
\hline $3.41-5.4$ & $948(49.8 \%)$ \\
\hline$>5.4$ & $324(17.0 \%)$ \\
\hline ND & $11(0.6 \%)$ \\
\hline \multicolumn{2}{|l|}{ Lymphovascular invasion } \\
\hline Positive & $492(25.9 \%)$ \\
\hline Negative & $1070(56.3 \%)$ \\
\hline ND & $340(17.9 \%)$ \\
\hline \multicolumn{2}{|l|}{ Operation type } \\
\hline Mastectomy & $1067(56.1 \%)$ \\
\hline WLE lumpectomy & $819(43.1 \%)$ \\
\hline ND & $16(0.8 \%)$ \\
\hline \multicolumn{2}{|l|}{ ER status } \\
\hline Positive & $1370(72.0 \%)$ \\
\hline Negative & $476(25.0 \%)$ \\
\hline ND & $57(3.0 \%)$ \\
\hline \multicolumn{2}{|l|}{ PR status } \\
\hline Positive & $1035(54.4 \%)$ \\
\hline Negative & $739(38.9 \%)$ \\
\hline ND & $128(6.7 \%)$ \\
\hline \multicolumn{2}{|l|}{ HER2 status } \\
\hline Positive & $243(12.8 \%)$ \\
\hline Negative & $1602(84.2 \%)$ \\
\hline ND & $57(3.0 \%)$ \\
\hline \multicolumn{2}{|l|}{ Basal status } \\
\hline Positive & $368(19.3 \%)$ \\
\hline Negative & $1390(73.1 \%)$ \\
\hline ND & $144(7.6 \%)$ \\
\hline \multicolumn{2}{|l|}{ Triple negative status } \\
\hline Positive & $315(16.6 \%)$ \\
\hline Negative & $1516(79.7 \%)$ \\
\hline
\end{tabular}

Table 1 (continued)

\begin{tabular}{ll}
\hline Variables & No. $(\%)$ \\
\hline ND & $71(3.7 \%)$ \\
Breast cancer-specific survival & \\
Alive & $1064(55.9 \%)$ \\
Dead & $505(26.6 \%)$ \\
ND & $333(17.5 \%)$ \\
Recurrence & \\
Present & $752(39.5 \%)$ \\
Not present & $1103(58.0 \%)$ \\
ND & $47(2.5 \%)$ \\
Distant metastasis & \\
Present & $579(30.4 \%)$ \\
Not present & $1310(68.9 \%)$ \\
\hline
\end{tabular}

Continuous data are shown as mean \pm standard deviation (SD)

$N P I$ Nottingham prognostic value; WLE wide local excision; $E R$ oestrogen receptor; $P R$ progesterone receptor; HER2 human epidermal growth factor receptor 2; $N D$ not determined

\section{TMA construction and immunohistochemistry}

MSK1 protein expression was investigated using freshly cut $4 \mu \mathrm{m}$ sections from tissue microarrays and assessed by immunohistochemistry. A single $0.6 \mathrm{~mm}$ tissue core was used for each patient with the core being taken from a representative tumour area as assessed by a specialist breast cancer histopathologist, as described previously (Abd ElRehim et al. 2005). A range of antibodies were assessed for suitability with primary antibody specificity being confirmed by Western blotting, using a range of breast cancer cell line lysates, prior to immunohistochemistry (data not shown). TMA sections were dewaxed in xylene and rehydrated in ethanol, followed by antigen retrieval, in $0.01 \mathrm{~mol} / \mathrm{L}$ sodium citrate buffer (pH6.0), using a microwave, $750 \mathrm{~W}$ for $10 \mathrm{~min}$ then $450 \mathrm{~W}$ for $10 \mathrm{~min}$. Staining was achieved using a Novolink Polymer Detection System (Leica, Denmark) according to the manufacturers' instructions. Briefly, endogenous peroxidase activity was neutralised with Peroxidase Block reagent for $5 \mathrm{~min}$ at room temperature, followed by Protein Block reagent for $5 \mathrm{~min}$ at room temperature, to minimise non-specific interactions of the subsequent detection reagents. Primary antibody (anti-MSK1, 1: 200, Bethyl Laboratories, USA, 9252) was diluted in Bond Primary Antibody Diluent (Leica, Denmark) and applied to the tissue for $1 \mathrm{~h}$ at room temperature. Immunohistochemical reactions were visualised with 3, 3'-diaminobenzidine and counterstained with haematoxylin, dehydrated and fixed in xylene followed by mounting with DPX. Positive controls constituted early stage breast tumour composite sections of varying grades, 
used in initial optimisations, and negative control omitted primary antibody.

Staining was assessed at $200 \times$ magnification following high-resolution scanning (Nanozoomer Digital Pathology Scanner, Hamamatsu Photonics). As no cytoplasmic staining was observed, only nuclear staining intensity was assessed. The staining intensity was categorised as: none (0), weak (1), medium (2) and strong (3). The immunohistochemistry $\mathrm{H}$-scores were calculated by multiplying the percentage of positive tumour cell nuclei by the staining intensity, giving rise to a score ranging between 0 and 300 . The immunohistochemistry methodology was described previously (Woolston et al. 2011a, b). 30\% of cases were scored by a second independent assessor, blind to survival endpoints, clinicopathological variables, and other assessors H-scores. Good concordance was demonstrated between both scorers (single measure intraclass correlation coefficient was 0.881). $\mathrm{X}$-tile software was used to generate a non-biased cut point that was used to dichotomise immunohistochemical scores (Camp et al. 2004).

\section{Statistical analysis}

Pearson's chi-squared test of association $\left(\chi^{2}\right)$ was used to examine the relationship between categorised protein expression and clinicopathologic factors, or Fisher's exact test if a cell count in a $2 \times 2$ table was less than 5 . Kaplan-Meier survival curves were plotted and significance was determined using the Log-rank test. The Cox proportional hazards regression model was applied in multivariate survival analysis. All differences were considered statistically significant at the level of $P<0.05$. Statistical analysis was performed using SPSS 22.0 software.

\section{Results}

\section{Immunohistochemical staining}

MSK1 demonstrated diffuse nuclear staining with some heterogeneity in intensity which varied from weak to intense. No cytoplasmic staining was observed. Areas of ductal carcinoma in situ (DCIS) showed variable staining intensity in some cases. Only cases of invasive cancer were scored. Typical staining patterns are shown in Fig. 1. TMA cores with insufficient tumour cells $(<15 \%)$ were not considered in the analysis. A total number of 1270 cases with informative cores were assessed. MSK1 staining had a median H-score of $190 \pm 83$ and ranged from 0 to 300 . X-tile software was used to generate a cut point best associated with outcome. This indicated an H-score of 115, with 364 cases (28.7\%) having low expression and 906 cases (71.3\%) having high expression.

\section{Relationships with clinicopathologic variables}

High MSK1 expression was significantly associated with patients over 40 years $\left(\chi^{2}=8.283, d f=1, P=0.004\right)$, lower tumour grade $\left(\chi^{2}=34.505, d f=2, P<0.001\right)$, lower NPI value $\left(\chi^{2}=9.804, d f=2, P=0.007\right)$, ER-positive tumours $\left(\chi^{2}=50.186, d f=1, P<0.001\right)$ and PR-positive tumours $\left(\chi^{2}=41.147, d f=1, P<0.001\right)$. Low MSK1 expression was significantly associated with the presence of triple-negative $\left(\chi^{2}=56.406, d f=1, P<0.001\right)$ and basal-like tumours $\left(\chi^{2}=13.850, d f=1, P<0.001\right)$. The associations between protein expression and clinicopathologic variables are shown in Table 2.

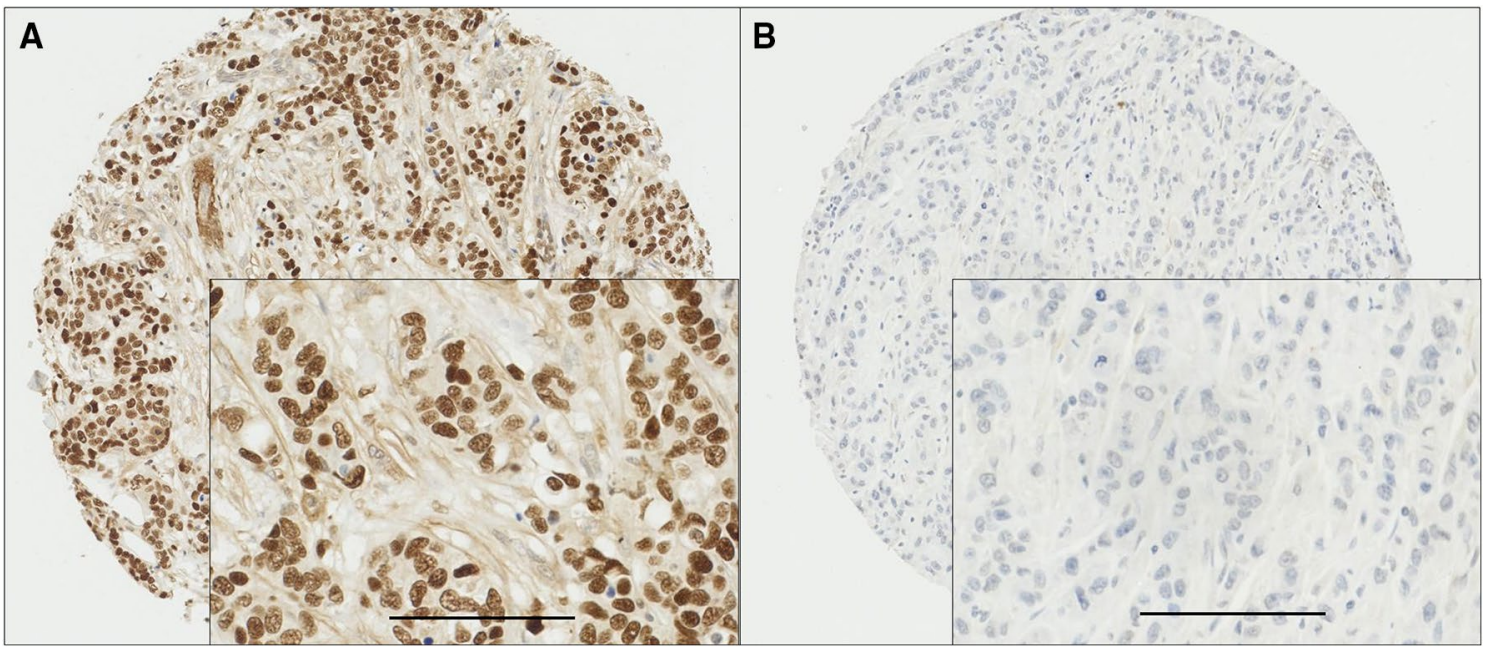

Fig. 1 Representative photomicrographs of high and low MSK1 expression. Panel A (high expression) and panel B (low expression) at $\times 10$ magnification with $\times 20$ magnification inset panel and scale bar representing $100 \mu \mathrm{m}$ 
Table 2 Associations between MSK1 protein expression and clinicopathologic variables

\begin{tabular}{|c|c|c|c|}
\hline \multirow[t]{2}{*}{ Variables } & \multicolumn{3}{|l|}{$\operatorname{MSK} 1(n=1270)$} \\
\hline & Low expression & High expression & $P$-value \\
\hline \multicolumn{4}{|l|}{ Age (years) } \\
\hline$\leq 40$ years & $49(3.9 \%)$ & $74(5.8 \%)$ & 0.004 \\
\hline$>40$ years & $315(24.8 \%)$ & $831(65.5 \%)$ & \\
\hline \multicolumn{4}{|l|}{ Tumour size (mm) } \\
\hline$\leq 20 \mathrm{~mm}$ & $207(16.4 \%)$ & $545(43.0 \%)$ & 0.275 \\
\hline$>20 \mathrm{~mm}$ & $156(12.3 \%)$ & $358(28.3 \%)$ & \\
\hline \multicolumn{4}{|l|}{ Tumour stage } \\
\hline I & $227(17.9 \%)$ & $540(42.7 \%)$ & 0.544 \\
\hline II & $105(8.3 \%)$ & $275(21.7 \%)$ & \\
\hline III & $30(2.4 \%)$ & $89(7.0 \%)$ & \\
\hline \multicolumn{4}{|l|}{ Tumour grade } \\
\hline I & $38(3.0 \%)$ & $169(13.3 \%)$ & $<0.001$ \\
\hline II & $96(7.6 \%)$ & $326(25.8 \%)$ & \\
\hline III & $229(18.1 \%)$ & $408(32.2 \%)$ & \\
\hline \multicolumn{4}{|c|}{ Nottingham prognostic index } \\
\hline$\leq 3.4$ & $85(6.7 \%)$ & $290(22.9 \%)$ & 0.007 \\
\hline $3.41-5.4$ & $198(15.7 \%)$ & $451(35.7 \%)$ & \\
\hline$>5.4$ & $79(6.3 \%)$ & $161(12.7 \%)$ & \\
\hline \multicolumn{4}{|c|}{ Lymphovascular invasion } \\
\hline Positive & $107(10.1 \%)$ & $248(23.4 \%)$ & 0.263 \\
\hline Negative & $190(17.9 \%)$ & $517(48.7 \%)$ & \\
\hline \multicolumn{4}{|l|}{ Operation type } \\
\hline Mastectomy & $213(16.9 \%)$ & $520(41.3 \%)$ & 0.682 \\
\hline WLE Lumpectomy & $147(11.7 \%)$ & $378(30.0 \%)$ & \\
\hline \multicolumn{4}{|l|}{ ER status } \\
\hline Positive & $205(16.7 \%)$ & $704(57.2 \%)$ & $<0.001$ \\
\hline Negative & $139(11.3 \%)$ & $183(14.9 \%)$ & \\
\hline \multicolumn{4}{|l|}{ PR status } \\
\hline Positive & $147(12.3 \%)$ & $538(45.0 \%)$ & $<0.001$ \\
\hline Negative & $196(16.4 \%)$ & $314(26.3 \%)$ & \\
\hline \multicolumn{4}{|l|}{ HER2 status } \\
\hline Positive & $49(3.9 \%)$ & $125(10.1 \%)$ & 0.894 \\
\hline Negative & $306(24.6 \%)$ & $762(61.4 \%)$ & \\
\hline \multicolumn{4}{|l|}{ Basal-like status } \\
\hline Positive & $96(8.1 \%)$ & $153(13.0 \%)$ & $<0.001$ \\
\hline Negative & $247(20.9 \%)$ & $685(58.0 \%)$ & \\
\hline \multicolumn{4}{|l|}{ Triple-negative status } \\
\hline Positive & $104(8.5 \%)$ & $109(8.9 \%)$ & $<0.001$ \\
\hline Negative & $237(19.4 \%)$ & $774(63.2 \%)$ & \\
\hline \multicolumn{4}{|c|}{ Breast cancer-specific survival } \\
\hline Alive & $577(41.7 \%)$ & $342(24.7 \%)$ & 0.01 \\
\hline Dead & $259(18.7 \%)$ & $207(14.9 \%)$ & \\
\hline \multicolumn{4}{|l|}{ Recurrence } \\
\hline Present & $167(13.5 \%)$ & $362(29.3 \%)$ & 0.013 \\
\hline Not present & $178(14.4 \%)$ & $530(42.8 \%)$ & \\
\hline \multicolumn{4}{|l|}{ Distant metastasis } \\
\hline Present & $138(11.0 \%)$ & $267(21.2 \%)$ & 0.002 \\
\hline Not present & $220(17.5 \%)$ & $635(50.4 \%)$ & \\
\hline
\end{tabular}

Correlations between MSK1 protein expression and clinicopathologic variables was assessed using Pearson's Ch-square test of association $\left(\chi^{2}\right)$ or Fisher's exact test if in a $2 \times 2$ tables and cell count was less than 5. Significant $P$ values are indicated by bold font
Table 2 (continued)

ER oestrogen receptor, $P R$ progesterone receptor, HER2 human epidermal growth factor receptor 2

\section{Relationships with clinical outcome}

Univariable survival analysis showed that low MSK1 expression was, in the whole patient cohort, significantly associated with worse breast cancer-specific survival $(P=0.009)$ (Fig. 2). Multivariate analyses including potential confounding factors, namely age at diagnosis, size, histologic stage, grade, NPI value, lymphovascular invasion, ER, PR and HER2 status (all variables with individual Kaplan-Meier statistics of $P<0.05$ ) were carried out to determine MSK1's independent prognostic value. MSK1 expression was not an independent indicator of breast cancer-specific survival [hazard radio $(\mathrm{HR})=0.899,95 \%$ confidence interval $(\mathrm{CI})$ $0.696-1.161 ; P=0.415]$.

Low MSK1 expression was also significantly associated with the development of distant metastasis $\left(\chi^{2}=13.850\right.$, $d f=1, P<0.001$ ), recurrence (including local/regional recurrence and distant metastasis) $\left(\chi^{2}=6.220, d f=1, P=0.013\right)$ and breast cancer-related death $\left(\chi^{2}=6.711, d f=1, P=0.01\right)$.

The prognostic significance of MSK1 protein expression was further assessed in different molecular phenotypes of breast tumours. As shown in Table 1, 243 (12.8\%), patients had HER2 + phenotype tumours, 315 (16.6\%) patients had triple-negative phenotype tumours, and 368 (19.3\%) patients had basal-like phenotype (as defined in the "methods" section) tumours. MSK1 expression was significant in both HER2 and basal-like groups (association with outcome breast cancer-specific survival) $(P<0.001$ and $P=0.022$, respectively, Fig. 2b, d). This was investigated further in the individual subgroups; low MSK1 expression was associated with adverse breast cancer-specific survival in HER2negative patients and patients with non-basal like disease $(P=0.006$ and $P=0.024$, respectively, Fig. $3 b$, f). No significant association was found in other individual subgroups (Fig. 3a, c-e). However, when including the previous confounding factors in multivariate analysis, MSK1 lost its independent prognostic value for breast cancer-specific survival in both the HER2-negative (hazard ratio $=0.860,95 \%$ confidence interval $0.649-1.141 ; P=0.295$ ) and non-basal like subgroup (hazard ratio $=0.938,95 \%$ confidence interval $0.695-1.266 ; P=0.674)$.

\section{Discussion}

This is the first study to describe the expression of total MSK1 protein in breast cancer patient tumour samples and to evaluate its prognostic significance. Low MSK1 


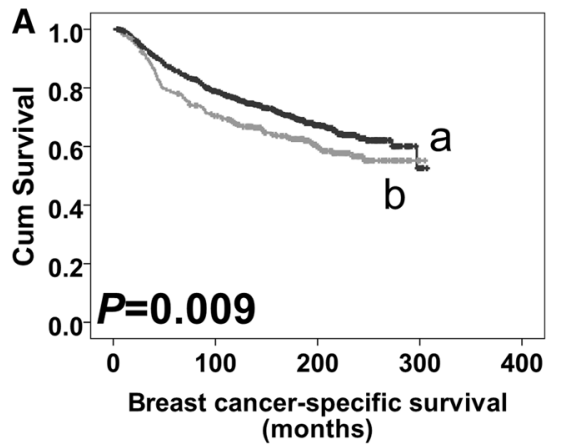

\begin{tabular}{l|ccccc} 
Group & 0 & 100 & 200 & 300 & 400 \\
\hline a High expression & 355 & 238 & 114 & 2 & 0 \\
b Low expression & 876 & 630 & 311 & 6 & 0
\end{tabular}

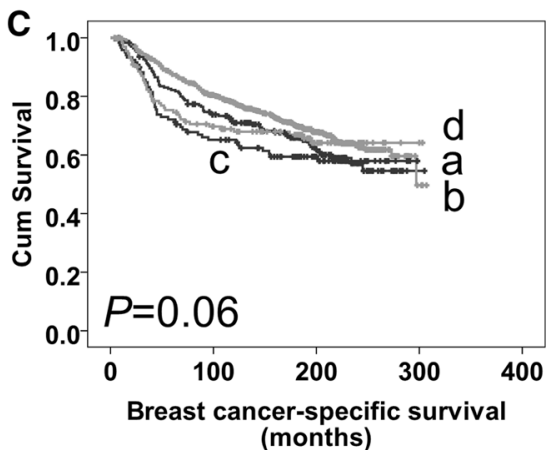

\begin{tabular}{l|ccccc}
\multicolumn{1}{c|}{ Group } & 0 & 100 & 200 & 300 & 400 \\
\hline a Non-TNeg, low MSK1 & 234 & 135 & 35 & $\mathbf{2}$ & 0 \\
b Non-TNeg, high MSK1 & 746 & 549 & 269 & 5 & 0 \\
c TNeg, low MSK1 & 119 & 75 & 42 & 0 & 0 \\
d TNeg, high MSK1 & 132 & 84 & 40 & 2 & 0
\end{tabular}

Fig. 2 Kaplan-Meier survival curves for breast cancer-specific survival based on MSK1 expression. Significance was determined using the log-rank test. Panel A: high MSK1 (a) and low MSK1 (b) expression in total patient cohort. Panel B: HER2-negative disease with low MSK1 expression (a); HER2-negative disease with low MSK1 expression (b); HER2-positive disease with high MSK1 expression (c); HER2-positive disease with high MSK1 expression (d). Panel C: non-triple-negative disease with low MSK1 expression (a); non-

expression was significantly associated with improved breast cancer-specific survival $(P=0.009)$; however, this was not significant in multivariate analysis.

High MSK1 expression was significantly associated with older patient age, lower tumour grade, lower NPI values, ERpositive and PR-positive tumours, and clinicopathological variables indicative of an improved prognosis. In agreement with this, low MSK1 expression was also found to be associated with the presence of distant metastasis, recurrence and death due to breast cancer, as well as the presence of triplenegative and basal-like disease. As MSK1 expression was associated with triple-negative and basal-like disease, the prognostic capability of MSK1 expression in these patient sub-groups was assessed. Patients with HER2 negative or
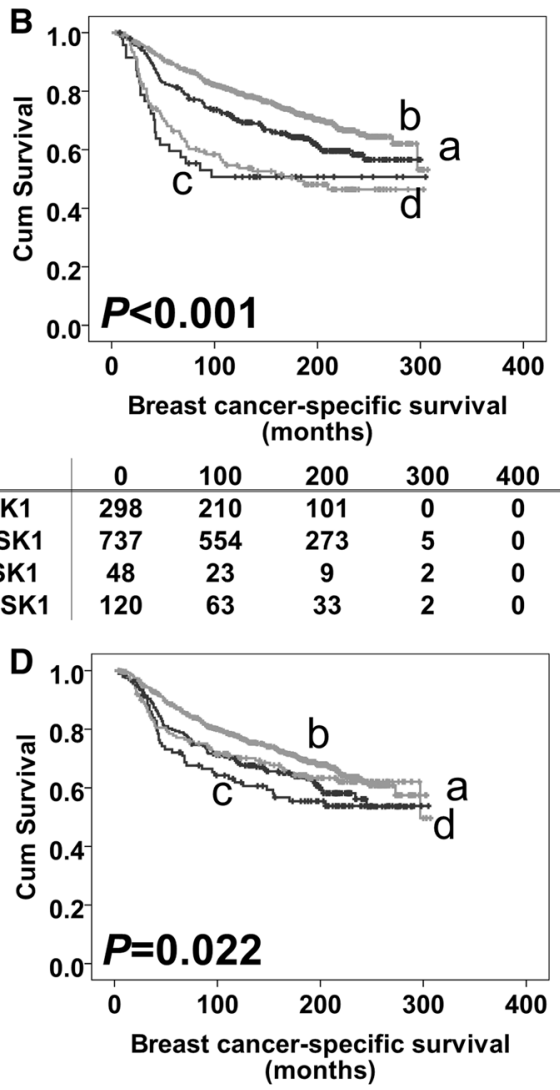

\begin{tabular}{l|ccccc} 
Group & 0 & 100 & 200 & 300 & 400 \\
\hline a Non-basal, low MSK1 & 242 & 165 & 69 & 0 & 0 \\
b Non-basal, high MSK1 & 664 & 481 & 229 & 3 & 0 \\
c Basal, low MSK1 & 93 & 57 & 36 & 2 & 0 \\
d Basal, high MSK1 & 150 & 100 & 57 & 4 & 0
\end{tabular}

triple-negative disease with low MSK1 expression (b); triple-negative disease with high MSK1 expression (c); triple-negative disease with high MSK1 expression (d). Panel D: non-basal-like disease with low MSK1 expression (a); non-basal-like disease with low MSK1 expression (b); basal-like disease with high MSK1 expression (c); basal-like disease with high MSK1 expression (d). The numbers below the survival curves are the number of patients at risk at the specified month

non-basal like diseases had a significantly worse prognosis if the tumour expressed low levels of MSK1.

Phosphorylated MSK1 has been shown to be significantly overexpressed in chronic UV-exposed murine skin, human squamous cell carcinoma (SCC) and poorly differentiated nasopharyngeal carcinoma compared with their normal tissue counterparts (Yao et al. 2014; Li et al. 2015). In the current study, total MSK1 expression, rather than phosphorylated MSK1, was assessed. Total MSK1 expression may not be indicative of MSK1 activity within cells; therefore, we cannot infer activity in this study. As mentioned before, many factors are substrates of MSKs and can be phosphorylated by MSK, such as CREB, ATF1, c-fos and histone H3 (Wiggin et al. 2002; Soloaga et al. 2003). Antibodies 

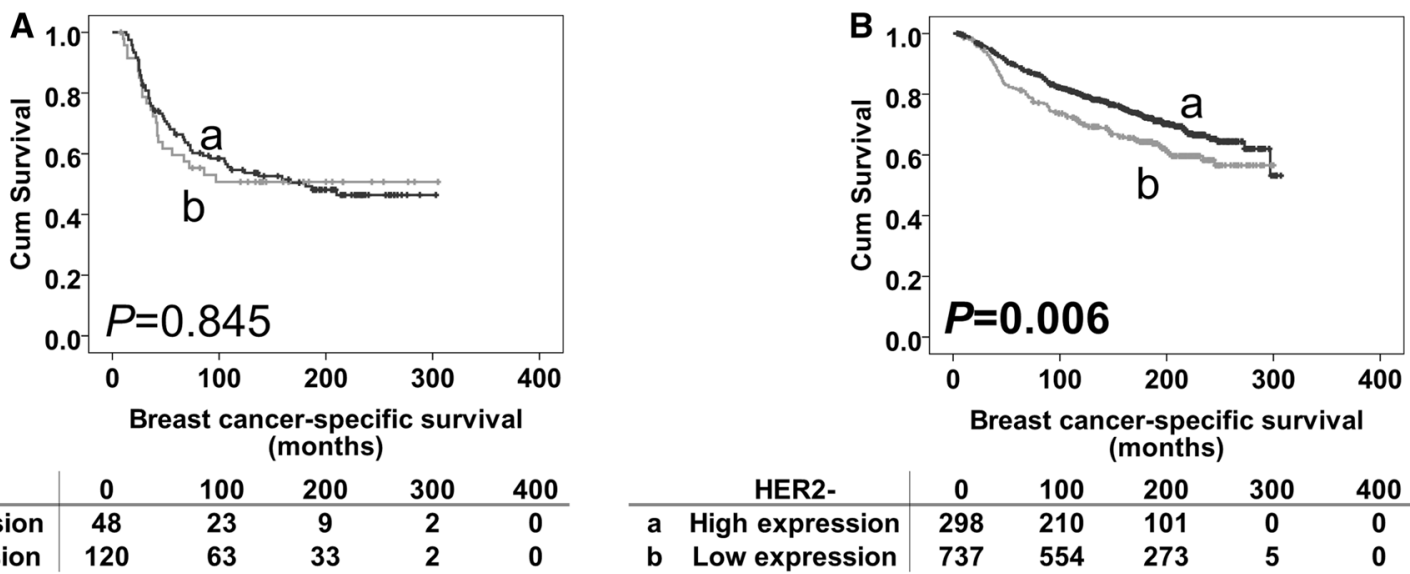

\begin{tabular}{|c|c|c|c|c|c|}
\hline \multirow[b]{2}{*}{ HER2+ } & \\
\hline & 0 & 100 & 200 & 300 & 400 \\
\hline High expression & 48 & 23 & 9 & 2 & 0 \\
\hline b Low expression & 120 & 63 & 33 & 2 & 0 \\
\hline
\end{tabular}

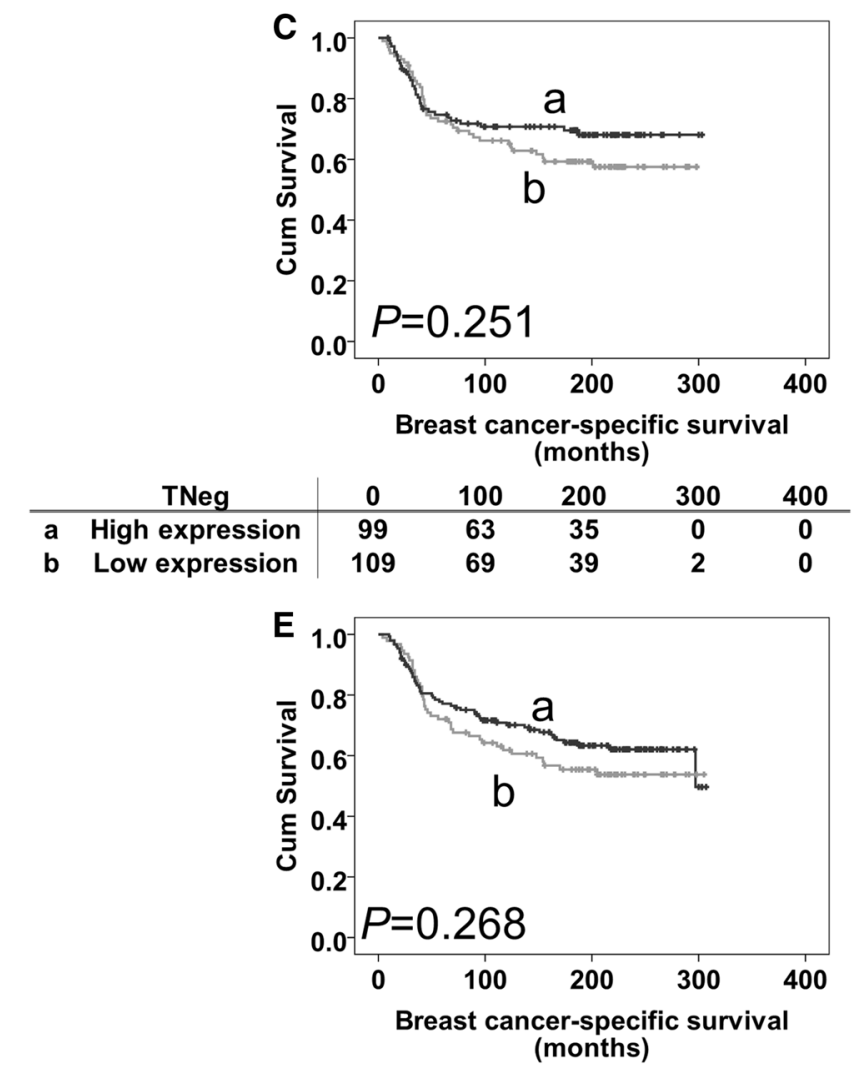

\begin{tabular}{cc|ccccc} 
& HER2- & 0 & 100 & 200 & 300 & 400 \\
\hline \hline a & High expression & 298 & 210 & 101 & 0 & 0 \\
b & Low expression & 737 & 554 & 273 & 5 & 0
\end{tabular}

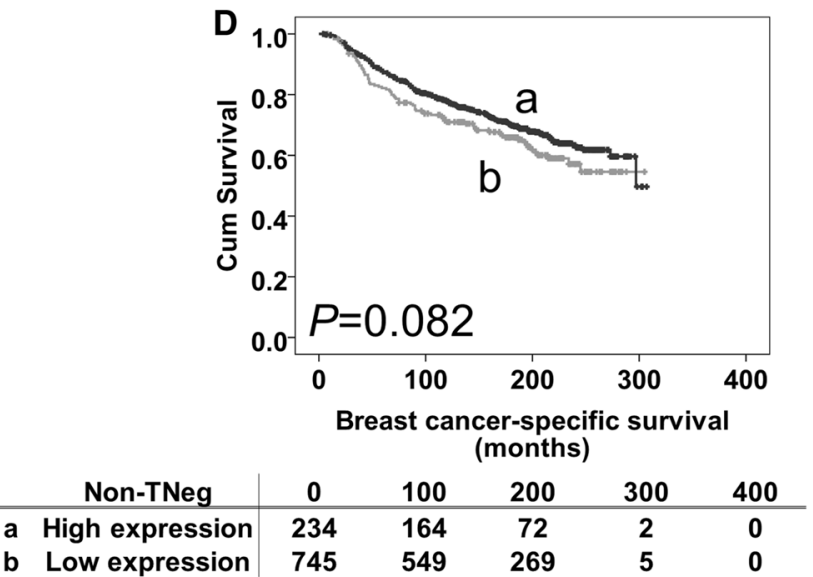

\begin{tabular}{ccccccc}
\hline a & High expression & 234 & 164 & 72 & 2 & 0 \\
b Low expression & 745 & 549 & 269 & 5 & 0
\end{tabular}

\begin{tabular}{cc|ccccc} 
& Basal-like & 0 & 100 & 200 & 300 & 400 \\
\hline a & High expression & 93 & 57 & 36 & 2 & 0 \\
b & Low expression & 150 & 100 & 57 & 4 & 0
\end{tabular}

Fig. 3 Kaplan-Meier survival curves for breast cancer-specific survival based on MSK1 expression in subgroups. Panel A: subgroup analysis of HER2-positive disease with high MSK1 expression (a) and low MSK1 expression (b). Panel B: subgroup analysis of HER2negative disease with high MSK1 expression (a) and low MSK1 expression (b). Panel C: subgroup analysis of triple-negative disease with high MSK1 expression (a) and low MSK1 expression (b). Panel

detecting specific MSK1 substrates might be a reflection of MSK1 activity in human breast tumour tissue. Low expression of $\mathrm{H} 3 \mathrm{~K} 27$ (with loss of trimethylation of histone $\mathrm{H} 3$ at Lysine 27) was also associated with adverse overall

\begin{tabular}{cc|ccccc} 
& Non-basal like & 0 & 100 & 200 & 300 & 400 \\
\hline a & High expression & 242 & 165 & 69 & 0 & 0 \\
b & Low expression & 664 & 481 & 229 & 3 & 0
\end{tabular}

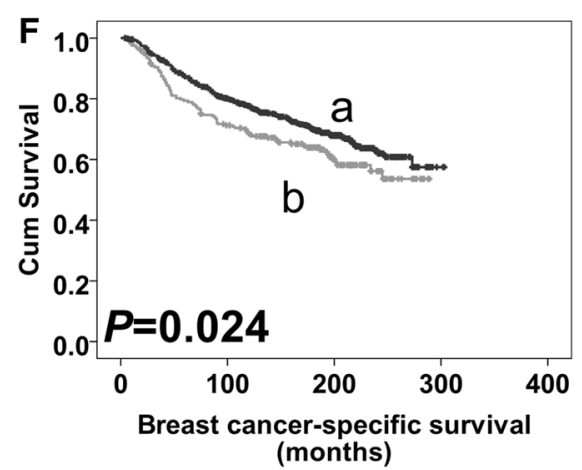

D: subgroup analysis of non-triple-negative disease with high MSK1 expression (a) and low MSK1 expression (b). Panel E: subgroup analysis of basal-like disease with high MSK1 expression (a) and low MSK1 expression (b). Panel F: subgroup analysis of non-basallike disease with high MSK1 expression (a) and low MSK1 expression (b). The numbers below the survival curves are the number of patients at risk at the specified month

survival in breast $(n=142)$, ovarian $(n=255)$ and pancreatic $(n=165)$ cancer patients (Wei et al. 2008). In addition, MSK1 activity in vitro (human embryonic kidney 293 cells) is tightly regulated by at least six phosphorylation sites; the 
mutation of some sites leads to decreased MSK1 activity or inhibition of other phosphorylation sites in MSK1 in cells (McCOY et al. 2005). It would be of interest to determine MSK1 expression in human tumour tissue by applying MSK1 antibodies with different phosphorylation sites and to explore whether MSK1 expression is regulated by a specific phosphorylation site.

Although MSK1 and MSK2 share similarity, they are different complexes and exert differing effects. Interestingly, differential roles of MSK1 and MSK2 in breast cancer cells following UV-radiation have been described. UV radiation has been shown to induce activation of the NF- $\mathrm{kB}$ p65 subunit in MDA-MB-231 cells, which is mainly dependent on MSK2 rather than MSK1. The depletion of MSK2 was found to reduce cell viability following UV radiation, suggesting that MSK2-mediated NF- $\mathrm{KB}$ activation is involved in regulating cell survival in MDA-MB-231 cells (Jacks and Koch 2010). Recently, MSK1 and MSK2 were also found to be involved in the regulation of phorbol ester-induced activation of trefoil factor 1 (TFF1), a breast cancer marker, in MCF-7 cells (Khan et al. 2013). It would be of interest to examine the potential differential roles of MSK1 and MSK2 in breast cancer cell progression, as well as their prognostic significance.

\section{Conclusions}

The current study demonstrates that low MSK-1 expression is significantly associated with adverse breast cancer-specific survival. Low expression seems to play a more important role in certain patient sub-groups, such as those with HER 2 + or basal-like phenotype disease. This is the first report to describe the potential prognostic significance of MSK1 expression in breast cancer patients; although not an independent marker of outcome, we believe such findings and significant associations with well-established negative prognostic factors (low expression associating with younger age, higher tumour grade, higher Nottingham Prognostic Index, negative hormone receptor status, shorter time to distant metastasis, and recurrence, and triple-negative/basallike status) warrant further examination and validation in independent patient cohorts.

Acknowledgements The authors gratefully acknowledge Breast Cancer Now for funding the research and SS (Ref: 2011MayPr35), a ViceChancellor's Scholarship for Research Excellence (University of Nottingham) for funding XP; Chris Nolan and Laurence Hall for technical assistance; and Mohammed A Aleskandarany for useful comments.

Author contributions XP and NA were responsible for data collection. $\mathrm{XP}$ and SS analysed the data. ER, AG and IE provided tissue and clinicopathological data. SM conceived the study. XP, SS and SM wrote manuscript. All authors approved the final version of the manuscript.
Funding The authors acknowledge Breast Cancer Now for funding the research and SS (Ref: 2011MayPr35), and a Vice-Chancellor's Scholarship for Research Excellence (University of Nottingham) for funding XP.

\section{Compliance with ethical standards}

Conflict of interest The authors declare that they have no conflict of interest.

Ethics approval Nottingham Research Ethics Committee 2 approved the project under "Development of a molecular genetic classification of breast cancer R\&D “(No. 03HI01 REC Ref.C202313)”.

Informed consent Additional informed consent was not required for the use of archived material prior to 2006 .

Open Access This article is distributed under the terms of the Creative Commons Attribution 4.0 International License (http://creativecommons.org/licenses/by/4.0/), which permits unrestricted use, distribution, and reproduction in any medium, provided you give appropriate credit to the original author(s) and the source, provide a link to the Creative Commons license, and indicate if changes were made.

\section{References}

Abd El Rehim DM, Ball G, Pinder SE, Rakha E, Paish C, Robertson JF, Macmillan D, Blamey RW, Ellis IO (2005) High throughput protein expression analysis using tissue microarray technology of a large well characterised series identifies biologically distinct classes of breast cancer confirming recent cDNA expression analyses. Int J Cancer 116(3):340-350

Abdel Fatah TM, Powe DG, Agboola J, Adamowicz Brice M, Blamey RW, Lopez Garcia MA, Green AR, Reis Filho JS, Ellis IO (2010) The biological, clinical and prognostic implications of p53 transcriptional pathways in breast cancers. J Pathol 220(4):419-434

Camp RL, Dolled-Filhart M, Rimm DL (2004) X-tile a new bio-informatics tool for biomarker assessment and outcome-based cutpoint optimization. Clin Cancer Res 10(21):7252-7259

Cargnello M, Roux PP (2011) Activation and function of the MAPKs and their substrates, the MAPK-activated protein kinases. Microbiol Mol Biol Rev 75(1):50-83

Deak M, Clifton AD, Lucocq JM, Alessi DR (1998) Mitogen-and stress-activated protein kinase-1 (MSK1) is directly activated by MAPK and SAPK2/p38, and may mediate activation of CREB. EMBO J 17(15):4426-4441

Hsu Y, Hou M, Kuo P, Huang Y, Tsai E (2013) Breast tumor-associated osteoblast-derived CXCL5 increases cancer progression by ERK/MSK1/Elk-1/snail signaling pathway. Oncogene 32(37):4436-4447

Jacks KA, Koch CA (2010) Differential regulation of mitogen-and stress-activated protein kinase-1 and-2 (MSK1 and MSK2) by CK2 following UV radiation. J Biol Chem 285(3):1661-1670

Khan P, Drobic B, Pérez-Cadahía B, Healy S, He S, Davie JR (2013) Mitogen- and stress-activated protein kinases 1 and 2 are required for maximal trefoil factor 1 induction. PLoS One 8(5):e63189

Lee HT, Kim SK, Choi MR, Park JH, Jung KH, Chai YG (2013) Effects of the activated mitogen-activated protein kinase pathway via the c-ros receptor tyrosine kinase on the T47D breast cancer cell line following alcohol exposure. Oncol Rep 29(3):868-874 
Li B, Wan Z, Huang G, Huang Z, Zhang X, Liao D, Luo S, He Z (2015) Mitogen-and stress-activated Kinase 1 mediates EpsteinBarr virus latent membrane protein 1-promoted cell transformation in nasopharyngeal carcinoma through its induction of Fra-1 and c-Jun genes. BMC Cancer 15(1):390

McCOY CE, Campbell DG, Maria D, Bloomberg GB, Arthur JSC (2005) MSK1 activity is controlled by multiple phosphorylation sites. Biochem J 387(2):507-517

McShane LM, Altman DG, Sauerbrei W, Taube SE, Gion M, Clark GM (2005) REporting recommendations for tumour MARKer prognostic studies (REMARK). Br J Cancer 93(4):387-391

Rakha EA, El-Rehim DA, Paish C, Green AR, Lee AH, Robertson JF, Blamey RW, Macmillan D, Ellis IO (2006) Basal phenotype identifies a poor prognostic subgroup of breast cancer of clinical importance. Eur J Cancer 42(18):3149-3156

Reyes D, Ballaré C, Castellano G, Soronellas D, Bagó J, Blanco J, Beato M (2014) Activation of mitogen-and stress-activated kinase 1 is required for proliferation of breast cancer cells in response to estrogens or progestins. Oncogene 33(12):1570-1580

Soloaga A, Thomson S, Wiggin GR, Rampersaud N, Dyson MH, Hazzalin CA, Mahadevan LC, Arthur JSC (2003) MSK2 and MSK1 mediate the mitogen-and stress-induced phosphorylation of histone H3 and HMG-14. EMBO J 22(11):2788-2797
Vermeulen L, Berghe WV, Beck IM, De Bosscher K, Haegeman G (2009) The versatile role of MSKs in transcriptional regulation. Trends Biochem Sci 34(6):311-318

Wei Y, Xia W, Zhang Z, Liu J, Wang H, Adsay NV, Albarracin C, Yu D, Abbruzzese JL, Mills GB (2008) Loss of trimethylation at lysine 27 of histone $\mathrm{H} 3$ is a predictor of poor outcome in breast, ovarian, and pancreatic cancers. Mol Carcinog 47(9):701-706

Wiggin GR, Soloaga A, Foster JM, Murray-Tait V, Cohen P, Arthur JSC (2002) MSK1 and MSK2 are required for the mitogen-and stress-induced phosphorylation of CREB and ATF1 in fibroblasts. Mol Cell Biol 22(8):2871-2881

Woolston CM, Al-Attar A, Storr SJ, Ellis IO, Morgan DAL, Martin SG (2011a) Redox protein expression predicts radiotherapeutic response in early-stage invasive breast cancer patients. Int J Radiat Oncol Biol Phys 79(5):1532-1540

Woolston CM, Storr SJ, Ellis IO, Morgan DAL, Martin SG (2011b) Expression of thioredoxin system and related peroxiredoxin proteins is associated with clinical outcome in radiotherapy treated early stage breast cancer. Radiother Oncol 100(2):308-313

Yao K, Chen H, Liu K, Langfald A, Yang G, Zhang Y, Yu DH, Kim MO, Lee M-H, Li H (2014) Kaempferol targets RSK2 and MSK1 to suppress UV radiation-induced skin cancer. Cancer Prev Res 7(9):958-967 